Inquiry

An Interdisciplinary Journal of Philosophy

ISSN: 0020-174X (Print) 1502-3923 (Online) Journal homepage: https://www.tandfonline.com/loi/sinq20

\title{
Why we should keep talking about fake news
}

\author{
Jessica Pepp, Eliot Michaelson \& Rachel Sterken
}

To cite this article: Jessica Pepp, Eliot Michaelson \& Rachel Sterken (2019): Why we should keep talking about fake news, Inquiry, DOI: 10.1080/0020174X.2019.1685231

To link to this article: https://doi.org/10.1080/0020174X.2019.1685231

曲 Published online: 27 Nov 2019.

Submit your article to this journal $₫$

山ll Article views: 261

Q View related articles $\sqsubset$

View Crossmark data \ulcorner 


\title{
Why we should keep talking about fake news
}

Jessica Pepp ${ }^{a}$, Eliot Michaelson ${ }^{b}$ and Rachel Sterken ${ }^{c}$

${ }^{\mathrm{a} D e p a r t m e n t}$ of Philosophy, Uppsala University, Uppsala, Sweden; ${ }^{\mathrm{b}}$ Department of Philosophy, King's College London, London, UK; 'Department of Philosophy, University of Oslo, Oslo, Norway

\begin{abstract}
In response to Habgood-Coote (2019. "Stop Talking about Fake News!" Inquiry: An Interdisciplinary Journal of Philosophy 62 (9-10): 1033-1065.) and a growing number of scholars who argue that academics and journalists should stop talking about fake news and abandon the term, we argue that the reasons which have been offered for eschewing the term 'fake news' are not sufficient to justify such abandonment. Prima facie, then, we take ourselves and others to be justified in continuing to talk about fake news.
\end{abstract}

ARTICLE HISTORY Received 20 September 2019; Accepted 20 October 2019

\section{Introduction}

In a recent paper (Pepp, Michaelson, and Sterken, forthcoming), we joined a growing number of philosophers (e.g. Levy 2017; Rini 2017; Aikin and Talisse 2018; Gelfert 2018; Lazer et al. 2018; Mukerji 2018; Fallis and Mathiesen, forthcoming) in offering a definition of one currently prominent use of the term 'fake news'. In doing so, we viewed this use of the term 'fake news' as a historical object (dating to approximately 2016), which came to be because a certain kind of phenomenon or activity became socially important in new ways around that time.

More specifically: A quick investigation on Google scholar suggests that before 2015, the term 'fake news' was used almost exclusively, at least in academic contexts, to refer to political satire or humor shows and sites. The use of this term changed precipitously around 2014-2016. (News articles about Paul Horner, the great fake newster, from 2014, express a kind of in-between understanding of the term, where what is still effectively satire is starting to be produced more for the purpose of being taken seriously.) The emergence of the new use of the term, e.g. as it 
was applied to Pizzagate, etc., marked an important societal shift. In our paper, we suggested that rapid changes in the way that news is produced and consumed made it the case that non-journalistically-produced stories could now be widely spread and treated as news - that is, they could be made to play many of the traditional roles for news - without concerted institutional efforts to achieve this and without clear limits on the scope and influence that these stories could have. It seems probable that the significance of this change played a role in giving rise to a new idiomatic use for the phrase 'fake news'.

We were interested in characterizing, describing, and delimiting the phenomenon that sparked the new idiomatic use for the phrase. We used the term 'fake news' for this phenomenon because that was the term that arose to name it. Prior to having a good description of a phenomenon, it is generally useful to have a name to call it by.

There are difficulties in sorting out what is 'essential' to this phenomenon, and what are merely accidental details of the way it has played out so far. Many social phenomena seem to raise analogous difficulties. Consider 'combatant', 'spousal abuse', 'intellectual property' or 'insider trading'. Words and phrases like these arise to name things we are regularly interacting with or thinking about, or social phenomena that we are actively engaged with. Then we struggle to figure out what the important aspects of those named phenomena are, so that we may gain a better ability to analyze, interact with, manage, or regulate them. Among the questions we may wish to answer are those of how long a given phenomenon has been around, how it has changed, and how it is differentiated from other, nearby phenomena. The same applies in the case of the phenomenon named as 'fake news'.

One might be tempted to conclude from all this that names are getting in the way of adequately addressing the phenomenon of fake news, and that the use of the term 'fake news' ultimately confuses matters. Instead of focusing on the term 'fake news', we should grapple directly with unambiguous descriptions of the regularities and patterns we encounter in our social world. Indeed, if it were equally easy for us to think directly about the underlying phenomena competing for our attention, described simply as they are, then there might be little reason for us to preserve contested or weaponized names like 'fake news'. But, we take it, part of why we often use a name to preliminarily fix our attention on some social phenomenon and then focus our inquiry around that name is that we are not all that good at homing in on the underlying phenomenon without this sort of attentional device. Still, even granting this point, 
there might be reasons to think that in the particular case of 'fake news', we, as academics, should stop using the term. Or so Joshua Habgood-Coote (2019) has recently argued. ${ }^{1}$ In this brief note, we will assess, and ultimately reject, his arguments. ${ }^{2}$

\section{Habgood-Coote's arguments}

Habgood-Coote argues that we should stop using the term 'fake news'. This injunction is meant to apply in particular to academics and journalists. Habgood-Coote offers three arguments in favor of his position, each of which he takes to be a sufficient reason for abandoning the term. The first is that 'fake news' is linguistically defective: the term is somehow meaningless, contested, or too unstable, vague, underdetermined, or inscrutable. The second is that the term is unnecessary: it doesn't add any descriptive resources to the language or allow us to do new things with words. The third is that the term has been weaponized for the purposes of propaganda or to denigrate the press and our news institutions. In what follows, we respond to each of these arguments in turn.

\subsection{Argument 1: 'fake news' has no stable meaning}

Habgood-Coote argues that the use of the term 'fake news' in ordinary, political, historical and academic settings is too varied and disparate to yield a stable meaning. As he puts it:

I suspect that if we were to carry out a proper study of linguistic usage, we would find speakers applying it in various incompatible ways. In Tandoc, Lim, and Ling's (2018) survey of academic usage, we see 'fake news' being applied to news satire, news parody, fabricated claims, photo manipulation, and to advertising. Farkas and Schou (2018) point out that 'fake news' is used as a political tool for a number of different projects, including giving a typology of types of false information, critiquing digital capitalism, critiquing right-wing politics and media, and critiquing liberal and mainstream media. One would hardly expect the folk who are using 'fake news' as a tool to undermine establishment media and to empower oppressed points of view to agree on the extension of the term.

\footnotetext{
${ }^{1}$ In advocating the abandonment of the term, he joins a number of others: Oremus 2016, 2017; Jack 2017; Sullivan 2017; Staines 2018; Talisse 2018; Wardle 2017; Zuckerman 2017; Finlayson 2019; Coady MS.

${ }^{2}$ For another response to Habgood-Coote which overlaps in some ways with this note and diverges in others, see Brown (forthcoming).
} 
The picture is complicated when we explore the history of the term. It seems to have originally meant just 'news that is fake' (Gelfert 2018 cites (MontgomeryMcGovern 1898)), before coming to be associated with satirical news shows (such as the Daily Show, and the Colbert Report), before coming to be associated with profit-driven clickbait producers (Silverman and Alexander 2016), finally acquiring a use as a catch-all for bad information, and a connection with journalistic bias. Each usage has a radically different extension, going someway toward explaining the current confusion around the term. (1039-1040)

Moreover, none of the many definitions of 'fake news' offered by academics and experts, according to Habgood-Coote, successfully specify the descriptive content of the term. No matter what metasemantic view of content determination one holds, there is reason to think the content of 'fake news' is not appropriately determined: speakers have conflicting beliefs about the meaning of 'fake news', they are disposed to use it in different ways, there is no unified expert usage to defer to, and the shifts of meaning of the term cut it off from any meaningful connection to its first use (1040-1041). As Habgood-Coote sees it, this raises the worrying possibility that the term is not merely context-sensitive or contested, but is nonsense: it has no descriptive content at all, so that in using it in speech or in thought one will fail to say or think anything. Without claiming that this is definitely the right diagnosis of the situation with 'fake news', Habgood-Coote proposes that it is a serious enough possibility that we should abandon the term just to be sure that we do not end up talking nonsense.

It seems to us that while such concerns might offer some reason to abandon a term, they are far from decisive. Many of our terms, especially terms which pick out important and complex social phenomena, exhibit the same kind of extensional and intensional uncertainties and linguistic defects that concern Habgood-Coote, over extended periods of time and to varying degrees. It can nonetheless be beneficial for speakers to live with such uncertainties and defects until the appropriate epistemic and linguistic/conceptual progress is made. It can take time for the semantic, metasemantic and epistemic properties of the term to crystalize, so to speak, for the given linguistic community. Consider the examples mentioned in the introduction: 'combatant', 'spousal abuse', 'intellectual property' and 'insider trading'.

Let's work through one of these in detail: we think most would agree that the term 'insider trading' is an important term, one that shouldn't be abandoned (nor should it have been abandoned at periods in its history when its semantic, metasemantic and epistemic properties may 
have been less settled than they are today). The term picks out, or at least aims to pick out, a socially significant phenomenon that governments and society ought to be tracking. ${ }^{3}$ The laws concerning insider trading are complex and vary greatly by country and jurisdiction. What counts as 'insider trading' varies depending on particular users' conceptions of what counts as an 'insider', as 'trading', as 'goods being traded', as 'publicly accessible information', and as 'profiting'. Further, some experts think that the term only applies if someone has suffered a significant amount of loss, has been harmed, or has been treated in a sufficiently unfair manner; that the term only applies if the trader made a sufficient gain as a result of the transaction; or that the term only applies given the standards set by certain legal precedents. All these factors compound the complexities already listed in correctly applying the term or grasping its meaning.

To make matters worse, like the term 'fake news', the evaluative and emotive content of 'insider trading' also varies for different groups of speakers: depending on one's political affiliations and one's relationships with business persons or traders, the normative evaluations and attitudes that are activated on an occasion of use of the term will differ. Finally, one might argue, these complexities surrounding the term 'insider trading' leave many important questions unanswered: Does 'insider trading' apply to off-market trades? Does it apply to trades that yield a profit of less than $\$ 10,000$ ? How does insider trading affect stock markets? Does 'insider trading' apply to trading done by the government, or by an algorithmic trading program? In sum, the term 'insider trading' seems to have a similarly varied set of uses and associations to those described by Habgood-Coote concerning 'fake news'. Whether the problems are severe enough to qualify 'insider trading' as lacking descriptive content altogether and so as being a nonsense term is perhaps unclear. But, as Habgood-Coote acknowledges, this is not clear in the case of 'fake news' either. Especially when we consider academics' use of 'fake news', the 'cornucopia of definitions' that Habgood-Coote lists certainly have differences, but they do not appear to carve out wildly different notions. ${ }^{4}$ The situation does not seem to be so different from that with 'insider trading'. And it seems clear that use of the term 'insider trading' is critical in asking and answering a number of important questions. (Nor is it hard to see how similar considerations apply to the other

\footnotetext{
${ }^{3}$ Even those that argue that insider trading should be legal would nonetheless think that we need the term and concept in order to track properties of economic markets and trading relations.

${ }^{4}$ Brown (forthcoming) details this convergence.
} 
examples of terms mentioned above.) By analogy, the case for abandoning 'fake news' does not yet seem clear.

Indeed, Habgood-Coote's line of reasoning concerning 'fake news' might suggest a blanket abandonment of many of our complex and socially significant terms. ${ }^{5}$ We are inclined to think that such blanket abandonment is unwarranted, but even if one thinks it is warranted, there is still the question of the degree to which such terms are actually defective.

To what extent do the observations above serve to underwrite the claim that the term 'fake news' is semantically defective? The patterns of usage of many of our terms - 'marriage', 'combatant', 'spousal abuse', 'intellectual property', 'insider trading', 'fake news', etc. - are extremely complex and hard to describe as a whole, even given the most sophisticated empirical tools in corpus linguistics. However, such complexity combined with our present inability to describe the usage patterns doesn't entail the kinds of metasemantic conclusions Habgood-Coote is inclined to draw, such as that shifts in meaning have cut the term off from its initial baptimal use and therefore that the term lacks meaning, or that no coherent grouping of dominant patterns emerges from the given complex package of usage facts. One can acknowledge that the usage facts are complex, and that there are numerous distinctive ways of using the term, but nevertheless claim that there are coherent meanings that accompany these distinctive ways of using the term.

Habgood-Coote also points to the fact that the term 'fake news' is highly contested as a reason for its abandonment. His reason for this is that when terms are contested we risk confusing metalinguistic disputes about the meaning of a term for substantive disputes about how the world is. But again, the fact that the meaning of a term is contested doesn't tell us anything directly about a term's descriptive content or lack thereof. We can argue about whether the Pope is a bachelor, but if any term has a clear descriptive content, 'bachelor' does. Likewise, even once it has been stipulated that a 'meter' is equivalent to the distance traveled by light in a vacuum in $1 / 299792458$ second, we are likely to argue about whether or not some particular object is a meter in length. It is implausible that either of these terms' meanings being contested would constitute a reason to abandon them. Perhaps things are different with 'fake news', but what that difference consists in remains to be specified.

\footnotetext{
${ }^{5}$ Here, Habgood-Coote's attitude resonates with that of Cappelen and Dever (2019, section 4.2), who seem willing to embrace the move from meaning being disputed to the conclusion that we ought to stop using the terms involved - at least until we have substantially reengineered those terms.
} 
An alternative way of accounting for the presence of contested analyses of 'fake news' is to claim that such definitions are stipulative, reclamatory or ameliorative. Academics and journalists trying to define the term 'fake news' take it to be the term that arose to name a phenomenon, or closely related set of phenomena, that interests us. The idea is to use the term to point to the phenomenon of interest prior to having a full characterization of that phenomenon. The disputes here can then be characterized as disputes regarding how best to characterize the relevant phenomenon, or perhaps about which of a number of closely related phenomena should serve as the primary object of our inquiry. ${ }^{6}$

None of this is to say that some uses of 'fake news' shouldn't be abandoned. Perhaps the use of the term 'fake news' to refer to comical news satire should now be abandoned, as it is apt to confuse matters to have that use in active circulation. And almost certainly those who put the term to bad propagandistic use should stop using it in these ways (see the third argument below for elaboration). All of what has been said above is consistent with this point.

\subsection{Argument 2: 'fake news' isn't necessary}

Habgood-Coote's second argument against using the term 'fake news' is that we don't need the term because we have other ways to describe all aspects of 'our current predicament'. He writes: 'We already have plenty of words for talking about deceit, miscommunication, and epistemic dysfunction. We can talk about lies, misleading, bullshitting, false assertion, false implicature, being unreliable, distorting the facts, being biased, propaganda, and so on' (1047). Perhaps it is right that the term 'fake news' is not needed for an accurate description of our situation. Indeed, we ourselves seem to be committed to this given that we have suggested a definition of 'fake news' in other terms. We and Habgood-Coote disagree over whether 'fake news' has descriptive content, but probably we agree that there are stories that are broadly spread and treated by those who spread them as having been produced by standard journalistic practices, but that have not in fact been produced by such practices. ${ }^{7}$ It is just that we think this constitutes fake news, while Habgood-Coote thinks there is no such thing as fake news, and the phenomenon we just described is

\footnotetext{
${ }^{6}$ Brown (forthcoming) makes similar remarks about how to see the debate over the definition of 'fake news'.

${ }^{7}$ This was our definition of 'fake news' in Pepp, Michaelson, and Sterken (forthcoming).
} 
one of many different things people might want to talk about in the arena of how democracies are faring epistemically. We should all agree that, given that we accept this definition and Habgood-Coote thinks there is no such thing as fake news, there is nothing about our current predicament we cannot describe without using the term 'fake news'. In general, any expression that can be defined in other terms is not needed to accurately describe how the world is. (Thus, if any of the definitions philosophers have attempted of terms including 'lies', 'bullshit', 'propaganda' and the like are correct, we do not need these terms either.) The question is whether the term is helpful in some way, not whether it is needed for an adequate description of things. ${ }^{8}$

One argument that the term 'fake news' is helpful would turn HabgoodCoote's concern about the term's well established negative evaluative content on its head. The fact that the term has this well-established negative content might be a reason for us to try to see to it that the descriptive content of the term is properly restrained. In a way, this is the converse of the standard sort of reclamation project regarding racial or gender slurs, where, instead of eliminating the term altogether, the effort is to retain the term's descriptive content while removing its negative evaluative content. To some extent, the choice of working toward elimination or working toward reclamation is a matter of which strategy looks likely to be most effective in modifying problematic behavior. Since 'fake news' expresses a certain sort of negative evaluation of news stories and it does not seem likely that people will drop the term altogether, it might be important to try to restrict its application (at least in academic and journalistic contexts) to those stories that actually merit the negative evaluation. We may need the term, and need to promote its being used correctly, precisely because it is now being used by many in unconstructive ways.

Another line of argument that Habgood-Coote offers against the need to reclaim the term 'fake news' is that if we focus too much attention on fake news (or, if he is right that there is no such thing as fake news, if we focus too much attention on various different phenomena like the one that our definition targets), we will end up ignoring many other issues related to epistemic dysfunction. If that's right, then this cost might outweigh whatever epistemic or practical benefits we accrue from talking about 'fake news'. In other words, if we can do without

\footnotetext{
${ }^{8}$ See also Fallis and Mathiesen (forthcoming) for a different sort of argument, via cases, to the effect that our ordinary epistemic vocabulary is unable to capture the phenomenon of interest.
} 
using the term while preserving our ability to inquire into the relevant phenomena, then perhaps we have reason to avoid using the term.

We are happy to grant that, if using the term 'fake news' really does have significant negative effects on our ability to inquire into a number of phenomena in the vicinity of fake news (or the phenomena that are being taken to constitute fake news), then this would be some reason to drop the term. But it is not clear how this negative effect is supposed to arise. Academics and journalists write about many different things and treat many different things as important, but we do not typically worry that in doing so they (or their colleagues) will be unable to treat other, related things as important. In fact, it seems to us that part of what treating something - e.g. bias in the news - as important amounts to is being able to distinguish between biased news and fake news.

Granted, there may be further grounds for concern. Habgood-Coote raises the possibility of terms like 'fake news' introducing bad ideology into the background of our conversation, thus undermining the possibility of rational analysis (1053). But it seems far from clear that this is the case, particularly when we are primarily interested in academic as opposed to mainstream discussions of fake news. Habgood-Coote suggests that even academics are subject to a tendency to classify all news as either real or fake, trustworthy or untrustworthy (1053-1054). But part of the philosophical investigation of the subject (including our own) has been aimed at making clear that real news can involve errors - even systematic errors and that there are other worrisome types of epistemic failures in the news beyond just outright error and whatever it is that might qualify some story as fake news (assuming there is such a thing). ${ }^{9}$

While we take the point that we, as academics, need to remain vigilant against the encroachment of unhelpful biases and background assumptions, if we are to follow through on Habgood-Coote's own suggestion that we need to come to grips with the variety of ways that news can fall short of what it should aspire to, epistemically and democratically, we can see little alternative to talking about 'fake news'. We need to be able to distinguish the underlying phenomenon here from other ways in which news sources can fall short of the ideal, and we need to be able to consider what sorts of remedies are appropriate for each. And while it is true that, strictly speaking, we could make do with descriptions of the relevant phenomenon or even introduce a neologism for it, we are

\footnotetext{
${ }^{9}$ See Saul (2018) for an instructive example. Saul points out that a certain type of false narrative in the news can be presented via sampling bias, bias which often comports with antecedent racial biases.
} 
not at all convinced that this will somehow prevent our antecedent biases and unhelpful background assumptions from merely latching onto these new ways of talking. On the contrary, we worry that assuming this to be the case might lead us to let our guard down, thereby potentially compounding the harm done by whatever biases and background assumptions we are apt to bring to the table in thinking about the effects of contemporary news more broadly, not just so-called 'fake news'.

\subsection{Argument 3: 'fake news' has propagandistic uses}

Habgood-Coote points out that the term 'fake news' is frequently used in propagandistic ways, both by governments to justify censorship or deny reported abuses, and by individuals (most notably, Donald Trump) to advance various political agendas. According to Habgood-Coote, the term 'fake news' is a paradigm instance of what Jason Stanley (2015) calls undermining propaganda, in that it is used to appeal to ideals such as truth, free exchange of ideas and an objective media in order to undermine those very ideals. This function of the term has led to its being 'weaponised', and given this we should simply drop the term to avoid unintentionally contributing to the spread of the ideologies promoted by undermining propaganda.

We certainly agree that 'fake news' is frequently used in propaganda, and in particular in propaganda that promotes what Habgood-Coote calls bad ideologies: 'any cluster of mutually supporting beliefs, practices, habits, and affective dispositions that is reasonably temporally persistent and socially extended' and (here is the bad part) 'which are false, mask reality, and are harmful' (1050). ${ }^{10}$ But the step from this point of agreement to endorsing the recommendation to drop the term is a large one. Consider the alternatives to 'fake news' Habgood-Coote offers as a means of describing 'our current predicament': 'We can talk about lies, misleading, bullshitting, false assertion, false implicature, being unreliable, distorting the facts, being biased, propaganda, and so on' (1047). The terms naming these phenomena are also used frequently in propaganda that promotes problematic ideologies - think of refrains like 'the lying news media' and 'the biased media'. It also seems plausible that in these propagandistic uses, terms like 'lie'/l'lying', 'bias' and so on would function to

\footnotetext{
${ }^{10}$ Habgood-Coote cites Stanley (2015) and Swanson (2017) as sources for these uses of 'propaganda' and 'ideology'.
} 
appeal to the same class of ideals as 'fake news' does, while simultaneously promoting goals that in fact undermine those ideals.

Given this, is there something special about the term 'fake news' that makes it a particularly dangerous linguistic tool with respect to promoting bad ideologies? Habgood-Coote does not address this question directly, but a few possibilities are suggested by his discussion. First, he mentions the 'powerful evaluative and expressive content of "fake news"'. While we do not deny that 'fake news' has such content, it seems that the other terms in the list given above also have such content, at least in the relevant contexts. Calling someone a 'liar' or a 'bullshitter' or saying that a news story is 'false', 'misleading' or a 'distortion of the facts' in the context of discussing media reliability is not only to describe stories, people, or institutions in these ways, but also to negatively evaluate their being these ways, and to express one's contempt or scorn for them.

Second, Habgood-Coote mentions that 'fake news' can function as an epistemic slur term - that is, as a term used to insult the epistemic character of the institution that produced the news story in question. This seems true enough, but it is also clearly the case that 'lies', 'bias,' 'bullshit' and the like can have a similar function. This is something that HabgoodCoote seems to recognize, claiming in a footnote that the word 'propaganda' can be used as an epistemic slur and thereby be 'stripped of its descriptive content' (1050, fn. 23). This might suggest that the real worry about a term being an epistemic slur is that being used in this way results in loss of descriptive content. And, indeed, Habgood-Coote points to 'lack of a stable descriptive content' as an important factor in allowing promoters of bad ideologies to use the term 'fake news' as they wish without having to face fact-based objections. The lack of stable descriptive content allows them to use whatever meaning of 'fake news' will make their allegations correct (1053).

Presumably there is supposed to be a contrast in this respect between 'fake news' and terms such as 'lies', 'bullshit', 'propaganda', etc. However, all of these terms refer to complex social phenomena whose analyses have been the subject of much philosophical debate and whose intuitive conceptual boundaries differ across social groups and individuals. So for the reasons given in section 1, it is unlikely that any of them will meet Habgood-Coote's standards for having a stable descriptive content. ${ }^{11}$

\footnotetext{
${ }^{11}$ Indeed, Habgood-Coote seems to recognize this, as noted above. But, he continues that same footnote, 'I hope to assuage this worry by associating the term with a clear descriptive content, and by distinguishing good and bad propaganda' (1050, fn. 23). It is worth noting that this is precisely what theorists seeking to define, and especially reclaim, the term 'fake news' are trying to do for it.
} 
But even if 'fake news' does have a less stable descriptive content than these other terms, it is far from clear that this is what allows promoters of bad ideologies to make powerful use of it. Quite probably, fact-based objections are ineffective against such accusations of 'fake news' because of the prominent role played by the evaluative and expressive content of the term. The accusers and their sympathetic audiences are more focused on the badness of the target and their dislike of it/them than they are on the facts about a specific news story. But, as we have already noted, Habgood-Coote's alternative terms have the same kinds of evaluative and expressive content in these contexts, and that content would be similarly in focus in such contexts if those terms were used instead of 'fake news'. For instance, when Trump accuses a media outlet of 'lying' or being 'biased', it is no more effective to respond that the story in question was not a lie, or was not biased, than it would be to say that it was not fake news, had that been the accusation. This, it seems to us, is not because Trump can easily switch to a meaning of 'lying' that makes his accusation true, but because it is the evaluative rather than the descriptive content of 'lying' that is important in these propagandistic contexts.

By the same token, it is not clear that academics using 'fake news' in academic discussions run a greater risk either of being perceived as using a slur term or of using a term lacking in descriptive content than they would if they only used terms such as 'lies', 'bias', 'propaganda' and the like in discussing phenomena such as the ones that we and other academics have pointed to as constituting fake news.

A third feature of the term 'fake news' that Habgood-Coote mentions is that it 'cue[s] up an ideology of media manipulation' (1052-1553). The idea here seems to be that this term is closely associated with a certain cluster of beliefs, practices and so on that are based on the supposed nefarious dishonesty of established producers of news stories. When people hear the term 'fake news', thoughts along these lines come to mind. Indeed, Habgood-Coote claims that 'fake news' can cue up two different ideologies, depending on the political leanings of the listener. In some, the ideology cued up might instead center on exaggerated views about the extent to which echo chambers and false news reports influence public opinion. Without getting into the details of how to understand this notion of cuing up ideologies, there does seem to be something to the idea that the term 'fake news' is more centrally associated with such patterns of thought and behavior than, say, the term 'lying'. But an obvious explanation for this is that 'lying' is a much broader term, which we 
apply in many different areas of life, whereas 'fake news' is a term that is specific to news media. Indeed, all of Habgood-Coote's suggested alternative vocabulary for talking about the phenomena that one might use 'fake news' to refer to - with the possible exception of 'propaganda' itself - are broader terms that do not specify the arena in which an epistemic demerit comes to be. When they are applied to news media and journalism specifically, they easily get connected to the relevant ideologies. It seems to us that Trump has already accomplished this with respect to describing the mainstream media as 'lying' or 'biased', and there is no reason why terms like 'false assertion', 'misleading' and the rest, when applied to various forms of media, could not similarly begin to function as 'cues' for the same ideologies. (Likewise, they could function to cue up the opposing ideologies about the outsized influence of misinformation.)

The ease of co-opting any epistemic vocabulary as a cue for various bad ideologies suggests that, at best, the reason we have to drop the term 'fake news' in favor of various other ways of describing the phenomenon of interest, is that, at the moment, the former is more strongly associated with certain bad ideologies than the latter. (Note that this is an empirical claim which would need to be established. ${ }^{12}$ ) This could easily change, which reveals a serious danger in the rule of thumb that HabgoodCoote endorses: 'When certain words become weaponised as tools for cuing up ideology, we should simply drop those words' (1058). The emergence of the use of the term 'fake news' that we described at the beginning of the paper marks an important social change in the way that news is produced, consumed and used. The appropriation of the term by Trump and others for bad propagandistic purposes obscures that change and its potentially problematic effects. If we cede the term to these speakers, we give up an important way to name and distinguish the phenomenon (that gave rise to the changed use of the term 'fake news') from other social phenomena. For now, Habgood-Coote may be right that we have other perfectly good vocabulary to do this with, but as the example of 'lying media' shows, this other vocabulary is just as vulnerable to appropriation by propagandists as 'fake news'. Thus, reclaiming the term 'fake news' may be part of a broader defense of our normative epistemic vocabulary. We should not surrender these terms lightly to propagandists and demagogues, since they are interconnected and vital to our collective ability to separate truth from falsehood.

\footnotetext{
${ }^{12}$ Brown points out (correctly, in our view) that the claim that all uses of 'fake news' serve to cue up such ideologies is a very strong empirical claim.
} 
Before closing, we also note that Habgood-Coote's suggested way of reacting to our current predicament regarding the term 'fake news' has some historical antecedents, and those do not offer much grounds for optimism. Reflect briefly on the practice of dropping words for various social groups once those words come to be viewed as involving some sort of slurring. In the good case, these words are then replaced with new ones that are deemed to be purely descriptive (e.g. the shift from 'Orientals' in the 80s/90s US to 'Asians', or the continual switch in words used to refer to people with disabilities). This process usually repeats itself - the new terms eventually come to be seen as pejorative as well. This is because the real problem (arguably, the fact that we categorize people in these ways at all, or perhaps the pervasiveness of negative attitudes towards the target groups) hasn't been addressed. Similarly, we can see no reason to think that refusing to use the word 'fake news' and switching to other ways of describing the phenomenon about which we wish to speak is going to remove the tendency on the part of bad actors to co-opt whatever words we come up with for the phenomenon as tools of propaganda and political weaponry. ${ }^{13}$

Furthermore, it is not clear that we have the same kinds of reasons to drop 'fake news' as we have to drop terms for social groups that acquire slurring uses. Even if it is likely that replacement words for the latter sorts of terms will themselves eventually acquire slurring uses, continuing to use the old terms is typically offensive and harmful to those who are treated as part of the relevant groups. Thus, we reduce certain social harms by continually updating our terminology to move away from tainted terms. By contrast, to the extent that 'fake news' is used as a slur, it can be directed against any news item or source that a speaker disapproves of. As Habgood-Coote points out, it can be directed against news sources considered 'mainstream' as well as against those considered 'fringe', on either side of the political spectrum. So, there is no particular group of people that inevitably will be singled out for offensive treatment by the continued use of 'fake news' in academic and journalistic contexts.

\section{Conclusion}

Habgood-Coote offers three main reasons for thinking that we should stop using the term 'fake news'. We have offered arguments to the effect that none of these reasons individually suffices to underwrite this conclusion.

\footnotetext{
${ }^{13}$ As Brown points out, all 'politically charged concepts' are vulnerable to being used in this way.
} 
Might they be jointly sufficient, however? We suspect not, though we can see the appeal of thinking the opposite.

Consider the following high-level description of a social game: there is a system of communication in which one is allowed to intercede. In that system, there is a certain signal $S$ which exhibits the following properties: (i) $S$ tends to be interpreted differently by different players; (ii) the use of $S$ is not required to achieve any collectively good outcome in the game; and (iii) $S$ is routinely used by 'bad' players to achieve local outcomes which are advantageous to them but harmful to most other players. Given this setup, suppose that one can intervene in two ways: one can do nothing, or one can ban the use of $S$. Which is the better way to intervene?

Conceiving of our present social state along these lines can make it tempting to look for the analog of intervening so as to ban the use of $S .^{14}$ But, of course, we have no such power in the real world - indeed, it is highly unclear that academics and journalists ceasing to use $S$ will have any effect on how other players play the game. Nor is it really the case that anyone is proposing to do nothing; on the contrary, academics and journalists are presumably trying to get a better handle on a problematic social phenomenon via their use of the signal. Even if the use of $S$ isn't required to achieve that, it may be a helpful expedient towards that end. Most significantly, however, knowing just this much about the game tells us nothing about whether intervening in this way is any more likely to lead to a good outcome or avoid a bad one. (iii) may make it tempting to think that a good outcome is more likely, but if the bad actors can, at little to no cost, replace $S$ with some signal $S^{*}$ that can serve the same purposes, then we have less reason to expect this to be true.

In a sense, this is just to say that it is hard to do social theory from the armchair, a fact that is as much a caveat to our own view as it is to Habgood-Coote's position. Presumably we all agree that in spite of its limitations, philosophical discussion of such questions is a vital part of a wider academic ecosystem. With such caveats duly noted, we are nonetheless skeptical that the background conditions necessary to make Habgood-Coote's recommended intervention (i.e. that academics voluntarily eschew the use of the term 'fake news') a virtuous one actually obtain. At present then, we think that we academics should keep talking about fake news. It seems to us that there is an interesting and important

\footnotetext{
${ }^{14}$ We don't mean to suggest that Habgood-Coote thinks we should somehow ban the use of 'fake news' in academic and journalistic writing. But his article encourages academics, at least, to achieve the same result by voluntarily eschewing it.
} 
social phenomenon - one which we take ourselves to have gone some way towards capturing in our recent paper - that the term 'fake news' is helpful for directing attention to. Since we find this phenomenon troubling, and suspect that it calls out for a thorough rethinking of some of our regulatory regimes, we take this term to be a useful tool to have. At the same time, we are skeptical that if we, academics and perhaps journalists as well, were to stop talking about 'fake news', this would have any salutary effects on the broader epistemic and political environment that we find ourselves in at present.

\section{Disclosure statement}

No potential conflict of interest was reported by the authors.

\section{References}

Aikin, Scott, and Robert Talisse. 2018. "On 'Fake News.'" 3 Quarks Daily, May 21. https:// www.3quarksdaily.com/3quarksdaily/2018/05/on-fake-news.html.

Brown, E. forthcoming. "Fake News' and Conceptual Ethics." Journal of Ethics and Social Philosophy.

Cappelen, Herman, and Josh Dever. 2019. Bad Language. Oxford: Oxford University Press.

Coady, David. MS. The Fake News about Fake News.

Fallis, D., and K. Mathiesen. forthcoming. "Fake News Is Counterfeit News." Inquiry: An Interdisciplinary Journal of Philosophy.

Farkas, Johan, and Jannick Schou. 2018. "Fake News as a Floating Signifier: Hegemony, Antagonism and the Politics of Falsehood." Javnost - The Public 25 (3): 298-314. doi:10.1080/13183222.2018.1463047.

Finlayson, Lorna. 2019. "What to Do with Post-Truth." Nordic Wittgenstein Review 8: 6379.

Gelfert, Axel. 2018. "Fake News: A Definition." Informal Logic 38 (2): 84-117.

Habgood-Coote, Joshua. 2019. "Stop Talking about Fake News!" Inquiry: An Interdisciplinary Journal of Philosophy 62 (9-10): 1033-1065.

Jack, Caroline. 2017. "Lexicon of Lie: Terms for Problematic Information.” Data \& Society. https://datasociety.net/pubs/oh/DataAndSociety_LexiconofLies.pdf.

Lazer, D. M., M. A. Baum, Y. Benkler, A. J. Berinsky, K. M. Greenhill, F. Menczer, M. Metzger, et al. 2018. "The Science of Fake News." Science 359 (6380): 1094-1096.

Levy, Neil. 2017. "The Bad News about Fake News." Social Epistemology Review and Reply Collective 6 (8): 20-36.

Montgomery-Mcgovern, J. B. 1898. "An Important Phase of Gutter Journalism: Faking." Arena 19 (99): 240-253.

Mukerji, Nikil S. 2018. A Conceptual Analysis of Fake News. https://philpapers.org/rec/ MUKACA. 
Oremus, W. 2016. "Stop Calling Everything 'Fake News."' Slate, December 6. http:// www.slate.com/articles/technology/technology/2016/12/stop_calling_everything_ fake_news.html.

Oremus, W. 2017. "Facebook Has Stopped Saying 'Fake News."' Slate, August 8. http:// www.slate.com/blogs/future_tense/2017/08/08/facebook_has_stopped_saying_ fake_news_is_false_news_any_better.html.

Pepp, Jessica, Eliot Michaelson, and Rachel Katharine Sterken. forthcoming. "What's New about Fake News?" Journal of Ethics and Social Philosophy.

Rini, Regina. 2017. "Fake News and Partisan Epistemology." Kennedy Institute of Ethics Journal 27 (S2): E-43-E-64.

Saul, Jennifer. 2018. "(How) Should We Tell Implicit Bias Stories?" Disputatio 10 (50): 217-244.

Silverman, C., and L. Alexander. 2016. "How Teens in the Balkans are Duping Trump Supporters with Fake News." Buzzfeed News, November 3.

Staines, C. 2018. "Why We Need to Stop Saying 'Fake News.'" https://fullfact.org/blog/ 2018/jan/fake-news/.

Stanley, Jason. 2015. How Propaganda Works. Princeton: Princeton University Press.

Sullivan, M. 2017. "It's Time to Retire the Tainted Term 'Fake News."' Washington Post, January 6. https://www.washingtonpost.com/lifestyle/style/its-time-to-retire-thetainted-term-fakenews/2017/01/06/a5a7516c-d375-11e6-945a-76f69a399dd5_ story.html.

Swanson, Eric. 2017. "Critical Notice of Jason Stanley's How Propaganda Works." Mind 126 (503): 937-947.

Talisse, R. 2018. "There's No Such Thing as Fake News (and That's Bad News)." 3:AM Magazine, June 9.

Tandoc Jr., E. C., Z. W. Lim, and R. Ling. 2018. “Defining 'Fake News' A Typology of Scholarly Definitions." Digital Journalism 6 (2): 137-153. doi:10.1080/21670811.2017.

Wardle, C. 2017. "Fake News. It's Complicated." First Draft, February 16. https:// firstdraftnews.com/fake-newscomplicated/30.

Zuckerman, E. 2017. "Stop Saying Fake News, It's Not Helping, My Heart Is in Accra." January 30. http://www.ethanzuckerman.com/blog/2017/01/30/stop-saying-fakenews-its-not-helping/. 